\title{
Репрессии на Барнаульском меланжевом комбинате накануне Большого террора: источниковедческий анализ следственных дел
}

\begin{abstract}
Аннотация. В данной работе представлен источниковедческий анализ трех следственнъх дел работников Барнаульского меланжевого комбината - одного из крупных объектов второй пятилетки. Рассматриваются следственнъе дела первого директора комбината М. Е. Гольдберга и его подчиненньх-заместителя директора К. Буторова и инженера-технолога К. Резникова, обвинявшихся в создании на комбинате в начале 1937 г. ячейки контрреволюиионного Сибирского иентра правых, связанного, по версии следствия, с Н. И. Бухариным, А. И. Ръковым и М. П. Томским. В исследовании используется микроисторический подход, сетевой анализ, анализ семантической структуры текста, архивная эвристика, общеисторический метод (историко-сравнительный). На основе показаний обвиняемьх реконструируется ход следствия, проводится анализ изменения статьи обвинения. Благодаря обнаружению в делах несогласованности в датах ареста, допросов, в показаниях, а также свидетельств нарушения уголовно-прочессуального кодекса РСФСР автор приходит к заключению о фабрикаиии рассматриваемъх следственных дел. Кроме указанных в статье приводятся примеры других следственных дел работников комбината, которые происходили с самого начала его работы в 1934 2.
\end{abstract}

Ключевые слова: Большой террор, источниковедение, следственное дело, Алтай, Барнаульский меланжевый комбинат, репрессии, М. Е. Гольдберг, вредители, контрреволюиионная деятельность, допрос.

Abstract. This article presents a source study examination of three investigation cases concerning workers at the Barnaul Melange Combine - one of the biggest enterprises of the second Five-year plan. Particular attention is given to the investigation case of the first director of the combine M. E. Goldberg and his subordinates - deputy director K. Butov and engineer-technologist K. Reznikov, accused of creating at the combine in the beginning of 1937 a counterrevolutionary cell of Siberian center-rightist, linked, according to the investigation, to N. I. Buhanin, A. I. Pykov and M. P. Tomsky. The article's research methodology uses the microhistory approach, network analysis, analysis of semantic text structure, archival heuristics, and the general historical method (historical-comparative). On the basis of the testimony of the accused, the author conducts an analysis in the altering of the original charged article of violation. Due to the discovery of inconsistencies in the cases regarding dates of arrest, interrogation, testimonies, as well as evidence of violation of the criminal-procedural codex of the Russian Soviet Federative Socialist Republic, the author comes to the conclusion that the investigation cases were fabricated. In addition to the noted examples, the article presents other investigation cases concerning combine workers that were opened at the very beginning of its operation in 1934.

Key words: Great Purge, source study, investigation case, Altai, Bernaul Melange Combine, repressions, M. E. Goldberg, enemies, counterrevolutionary activity, interrogation.

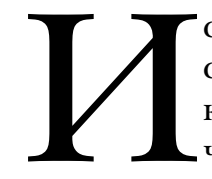
сториография политических репрессий в СССР содержит значительное количество работ, посвященных причинам начала репрессивных кампаний, их ходу и последствиям. Как правило, такие работы концентрируются на всесоюзных процессах. Рассмотрению региональных особенностей репрессий уделяется не так много внимания. В основном анализируются процессы, проис- ходившие в регионах в годы Большого террора (1937-1938 гг.), они могут быть проиллюстрированы конкретными примерами отдельных следственных дел. В этот период террор носил определенную специфику: существовали утвержденные «сверху» квоты на репрессии, которые местные органы НКВД должны были выполнять в обязательном порядке. В предшествующие Большому террору два с половиной года не су- 


\section{Исторический журнал: научные исследования № 5 (35) • 2016}

DOI: 10.7256/2222-1972.2016.5.20378

ществовало четко установленных репрессивных квот, следовательно, возникает вопрос о том, кто и по каким причинам становился жертвой террора. В данной статье на материалах следственных дел по Алтаю (они хранятся в отделе спецдокументации управления архивного дела Алтайского края, сокращенно ОСД УАДАК), которые позволяют реконструировать ход следствия, мы рассмотрим, как была «создана» одна из многочисленных групп «контрреволюционеров», «вредителей» и «шпионов».

После убийства С.М. Кирова 1 декабря 1934 г. в СССР началась новая (после раскулачивания) волна репрессий. Затронув сначала лишь верхушку власти, она постепенно разрасталась, втягивая в себя широкие слои населения. Виновных начали искать повсюду: с начала 1936 г. Сталину стали поступать сообщения о сильном сопротивлении стахановскому движению, что было недопустимо в условиях продолжающейся индустриализации. Она проходила нелегко: к примеру, в сентябре 1936 г. на кузбасской шахте «Центральная» прогремел взрыв. На суде «выяснилось», что диверсию организовала подпольная троцкистская группа в сговоре с инженерами из числа старых «спецов», что нити заговора тянулись в Москву. Это стало поводом для усиленного выявления «вредителей» и «врагов» на производстве. С октября 1936 г. частыми стали аресты не только среди руководителей предприятий и учреждений, но и рядовых советских работников [1, с. 94].

Репрессии не могли обойти стороной и регионы, в особенности Западно-Сибирский край, на территории которого находилась шахта «Центральная». Очевидно, что немногие аресты на промышленных предприятиях были напрямую связаны со взрывом, однако они отражали общую тенденцию, характерную для всей страны в целом.

В 1936 г. в г. Барнауле было 74 промышленных предприятия [2, с. 131]. Одним из наиболее крупных и стратегически важных объектов являлся Барнаульский меланжевый комбинат (БМК). Репрессии на нем кратко рассматривались как в научной [3, с. 11]; [4, с. 123-126], так и публицистической литературе [5]. Целью нашей работы является рассмотрение одного из наиболее неблагоприятных периодов за время существования комбината - 1937 года - на примере следственного дела первого директора БМК и начальника его строительства М.Е. Гольдберга. Для реализации поставленной задачи нами будет проведен источниковедческий анализ трех следственных дел репрессированных.
Решение о строительстве комбината было принято на XVII конференции ВКП(б) в январе 1932 г. Уже в феврале по проекту, разработанному московскими специалистами, началось строительство, однако проектировщики даже не видели строительную площадку. Строительство должно было вестись «социалистическими темпами», что при отсутствии подготовительных работ вызвало брак. Как писал алтайский краевед В.Ф. Гришаев, к моменту торжественной закладки фундамента 21 июня не было ни сметы, ни проекта организации работ, не была спланирована стройплощадка, и к месту стройки даже не была проложена дорога. Все это привело к проблемам с водо- и электроснабжением, что создавало трудности для организации стабильной работы прядильного цеха, в котором из-за указанных проблем, а также недостатка квалификации персонала происходили частые поломки оборудования [5, с. 14]. В обстановке тотального недоверия и поиска постоянных «врагов» и «вредителей», такое положение на БМК не могло укрыться от органов государственной безопасности.

6 августа 1934 г. считается днем рождения комбината. Но в какой обстановке начинал свою работу столь крупный объект второй пятилетки? По информации базы данных «Мемориала», уже в декабре 1934 г. на комбинате было арестовано 7 человек. Одной из обвиняемых по данному делу была Т. Пепеляева, буфетчица ОРСа, 1913 г.р.[6, Л. 34]. Обвинение состояло в том, что Пепеляева совершила умышленный поджог в здании Меланжевого комбината. Очевидно, что дело не готовилось заранее: в нем отсутствуют документы, связанные с задержанием (по классификации С.В. Журавлева [7, c. 375].): справка на арест, ордер на обыск, протокол обыска. На это указывает и тот факт, что Пепеляева была арестована на следующий день после пожара, 16 декабря 1934 г. В постановлении о предъявлении обвинения указана статья 58-8 [6, Л. 27], что, вероятно, является ошибкой следователя, так как данная статья предусматривала наказание за совершение террористических актов против представителей Советской власти, в отличие от статьи 58-9, устанавливающей ответственность за порчу любого государственного или общественного имущества. Остальные фигуранты данного дела изначально обвинялись именно по ст. 58-9.

С обвиняемой было проведено два небольших допроса - 16 и 22 декабря. На первом она показала, что в день пожара не вышла на работу 
по причине плохого самочувствия, однако заходила в помещение буфета вечером для того, чтобы забрать бумаги для составления еженедельного отчета. В помещении буфета она провела немного времени, зажигала там электрическую лампочку, затем закрыла его на замок и пошла на квартиру истопницы Гевлевой. После этого она вернулась домой и увидела пожар. Виновной в совершении поджога Пепеляева себя не признала [6, Л. 36]. На втором допросе следователь Изосимов задал Пепеляевой вопрос о том, кого она подозревает в совершении поджога, и она показала на мужа истопницы обозника Гевлева. На вопрос, почему она не дала показания сразу, Пепеляева ответила, что она хотела узнать, как работает ГПУ, поэтому не отвечала на вопросы прямо во время первого допроса [6, Л. 37]. 23 декабря 1934 г. Пепеляева повесилась в своей камере, написав на стене: «Прощайте Изосимов, я больше к вам не приду, только вы один мне понравились, я полюбила вас как товарища». Комиссия, расследующая дело о самоубийстве Пепеляевой, заключила, что его причиной не мог стать арест, так как обвиняемая находилась в камере всего неделю и в хороших условиях [6, Л. 39-40]. Причиной пожара же стали проблемы с электропроводкой, экспертное заключение по которым также присутствует в материалах дела, а также запертая дверь буфета, которая усложнила пожарникам доступ в помещение.

Всего в базе данных «Мемориала» присутствует информация о 443 работниках комбината, репрессированных в период с 1934 до 1953 гг. Большая их часть (403 чел.) была арестована после объявления решения Бюро Запсибкрайкома ВКП(б) от 25 июня 1937 г. «О выполнении директив пленума ЦК ВКП(б) по ликвидации последствий вредительства на Барнаульском меланжевом комбинате». В нем сообщалось, что руководство комбината не сделало ничего, чтобы ликвидировать последствия вредительства на комбинате, в связи с чем начальник комбината Гусев и секретарь парткома Флорен обязаны были к 10 июля 1937 предоставить план конкретных мероприятий по ликвидации вредительства и сделать доклад об его осуществлении в первых числах августа [8, Л. 179]. Отметим, что М.Я. Флорен был арестован 8 августа 1937 г. и 29 июня 1938 г. приговорен к высшей мере наказания [9].

В рассматриваемый нами период с 1 декабря 1934 г. по 30 июня 1937 г. на БМК было арестовано 40 человек. Дела 11 из них были завер- шены в период Большого террора и после его окончания, в 1939 г. В это число вошел и первый директор Меланжевого комбината Максим Ефимович Гольдберг. Компрометирующий материал на него, как и на других работников комбината, собирался задолго до ареста, с 1935 г. По данным В.Ф. Гришаева, на БМК работал спецотдел, который докладывал в городской отдел НКВД о каждой аварии, простое, поломке с указанием виновных [5, с. 22]. Среди документов Алтайского государственного архива есть запросы комбината в УНКВД о социальном происхождении, лишении избирательных прав, а также политической характеристики на работников БМК. Такие запросы во многих случаях сигнализировали о последующих арестах. Приведем пример: 15 февраля 1935 г. комбинат запросил характеристику на слесаря А. Глубокова, который имел неблагоприятное социальное происхождение [10, Л. 38]. 21 декабря 1937 г. он был арестован, обвинен по ст. 58-9-11 и 10 ноября 1938 г. приговорен к высшей мере наказания. Характеристика на другого слесаря - М. Фавстрицкого - была запрошена 14 сентября 1935 г. [10, Л. 53]. 13 ноября 1937 г. он был арестован, обвинен по ст. 58-210-11 и 27 ноября 1937 г. приговорен к расстрелу.

Как уже упоминалось ранее, спецотдел собирал информацию и на М. Гольдберга. Он приехал в Барнаул из Иваново-Вознесенска в 1932 г., где также руководил меланжевым комбинатом. Ранее с 1918 по 1928 гг. Гольдберг работал в управлении ВЦСПС под руководством М.П. Томского. В 1923 г. он дал партийную рекомендацию меньшевику, который впоследствии был арестован [5, с. 15]. Два этих факта явно служили отягчающими обстоятельствами при формировании политической характеристики Гольдберга.

Арест Гольдберга явно готовился заранее. 30 января 1937 г. он был выведен из состава парткома комбината, 1 февраля исключен из партии как «двурушник и враг народа» [11]. 12 марта 1937 г. Гольдберг был арестован. В справке на его арест значилось следующее: «В январе месяце 1937 года 4 отделом УГБ УНКВД по ЗСК в г. Новосибирске был вскрыт и ликвидирован Сибирский контрреволюционный центр правых, <..> который по указанию Союзного центра до момента ликвидации вел активную террористическую и разрушительную работу. Следствием установлено, что в мае 1934 г. по прямой директиве члена Союзного центра правых Томского, лично знавшего Гольдберга как активного члена контрреволюционной 


\section{Исторический журнал: научные исследования № 5 (35) • 2016}

DOI: 10.7256/2222-1972.2016.5.20378

организации, Гольдберг М.Е. был введен в состав Западно-Сибирского террористического центра, <...> Кроме того установлено, что Гольдберг как член руководящего центра Западно-Сибирской контрреволюционной организации правых лично организовал контрреволюционную вредительскую группу правых на Барнаульском меланжевом комбинате и руководил ее практической контрреволюционной разрушительной деятельностью». Гольдберг был также обвинен в срыве своевременного строительства цехов, в срыве работ, создании брака, трех авариях на ТЭЦ комбината и в организации массового отравления рабочих [12, Л. 1-3]. В постановлении о предъявлении обвинения значилась статья 58-7-11 [12, Л. 6], в корешке ордера на обыск 58-7-10-11 [12, Л. 8]. Очевидно, что в справке на арест не присутствовало обвинений в проведении антисоветской агитации (пункт 10 ст. 58), следовательно, не понятно, по каким причинам этот пункт появился в ордере на обыск.

Напомним, что все хозяйственные нарушения, предъявленные Гольдбергу в качестве обвинения, являлись следствием «социалистических», ускоренных темпов строительства при отсутствии его плана, техники и материалов. Инцидент с отравлением рабочих подробно описан у В.Ф. Гришаева: отопительные батареи были покрашены кузбасслаком, от которого несколько человек «угорело», однако на следующий день они вышли на работу. Эта история также не укрылась от глаз следователей [5, с. 18]. Однако сам Гольдберг начал давать признательные показания уже с первого допроса. На втором, который проходил 4-5 апреля 1937 г., он указал, что организация правых усилила свою деятельность тем, что заключила блок с троцкистами, которые также признают одним из наиболее реальных методов борьбы со Сталиным и руководством ЦК ВКП(б) терpop [12, Л. 20]. В данном контексте Гольдберга обвиняли в планировании убийства первого секретаря Западно-Сибирского крайкома ВКП(б) Р.И. Эйхе. Под троцкистами подразумевались, в первую очередь, люди, приехавшие на работу в Барнаул из Иваново-Вознесенска по приглашению Гольдберга: Н. Рабинович, О. Адлер и А. Ноговицын (или Наговицын, следователи писали его фамилию по-разному, арестован 13 февраля 1937 г., приговорен и расстрелян 29 июня 1938 г.). Гольдберг знал их как хороших специалистов, однако все они имели связи с «троцкистами» - родственные или рабочие. Гольдберг отстаивал честь этих людей на партийном собрании комбината, за что и был исключен, а также сам вписан в состав троцкистов [5, c. 15-16]. Он также в ответе на вопрос, кто входил в состав Союзного центра правых, показал, что Томский называл ему себя, Н.И. Бухарина и А.И. Рыкова [12, Л. 20]. Это соответствовало общей политической ситуации в стране: во время Второго Московского процесса против Бухарина были выдвинуты очередные обвинения, поэтому вскрытие «контрреволюционной группы» на крупном объекте второй пятилетки, «напрямую связанной» с руководителями Союзного центра, служило бы необходимым отягчающим для него обстоятельством.

Обличительным инструментом «преступлений» начальника БМК также выступила социалистическая пресса. В деле Гольдберга имеется газетная публикация под заголовком «О троцкистском укрывателе Гольдберге и задачах коллектива» (вероятно, вырезка сделана из газеты «Красный Алтай», периодически освещавшей ситуацию на комбинате»). В данной статье сказано, что в 1936 г. комбинат не выполнил плана, а сам год был периодом сплошных аварий. Виной этому являлось то, что комбинатом руководил «матерый адвокат и укрыватель всякого рода троцкистских и антисоветских элементов Гольдберг». Сообщалось, что он защищал исключенного из партии троцкистского адвоката Наговицина, продолжал дружбу с разоблаченной троцкистской Адлер, прикрывая это дружбой жены. По поводу аварий Гольдберг давал следующие «троцкистские» объяснения: «Крыша плохая, потому что проект неправильный. Отравление рабочих произошло потому, что угольный лак на сильно нагревшихся батареях выделил угарный газ». «В этих объяснениях нет ни малейшего намека на людей - сам проект «проектировался», сами по себе и батарей нагревались и красились именно в тот момент, когда политически выгодно навредить» подытоживал автор публикации [12, Л. 103].

По существу своей «вредительской» работы Гольдберг показывал, что еще в 1935 г. привлек в группу «правых» заместителя начальника строительной части К. Леонтьева (арестован 18 октября 1937 г. в должности начальника строительства БМК, приговорен и расстрелян 29 июня 1938 г.), а затем в 1936 г. своего заместителя К. Буторова. В протоколе несколько раз звучала фраза «на предыдущих допросах», хотя до 4 апреля он был всего один. Гольдберг «сознался» и в установлении связей с герман- 
ским консульством и в «прямом служении фашистам» [12, Л. 26, 28, 31], что означало обвинение в шпионаже. Однако есть основания полагать, что сам Гольдберг не знал о приписываемых ему новых обвинениях, так как подпись, стоящая в конце протокола второго допроса, не похожа на предыдущие подписи обвиняемого [12, Л. 30]. Третий протокол допроса он, вероятно, снова подписал самостоятельно - подпись больше похожа на две, стоящие под первым протоколом допроса [12, Л. 52].

В деле не присутствует ни одного документа о смене статьи обвинения, однако в группе документов, относящихся к окончанию следствия и его итоговым материалам (протокол об окончании следствия, обвинительное заключение, протокол судебного заседания, приговор), пункты статьи 58 меняются неоднократно. В протоколе об окончании следствия от 29 октября 1937 г. значится статья 58-7-8-9-11 [12, Л. 226]. В обвинительном заключении, составленном в этот же день, сказано, что Гольдберг являлся активным участников контрреволюционной шпионско-диверсионной террористической организации (она была выявлена в июле-августе 1937 г. и состояла уже не только из работников БМК. Ее «главой» был заместитель председателя Краевого исполнительного комитета Грядинский, в составе был Фомин - начальник Краевого заготовительного управления - его Гольдберг в своих показаниях называл связующим звеном с германским консульством). В этом заключении (на первой странице - по ст. 58-1a-2-8-11 [12, Л. 229]) вредительство на БМК уходило на второй план по сравнению с другими обвинениями - «исчезли» пункты 7 и 9, однако на последней странице пункт 9 появился вновь: теперь обвинение выдвигалось по ст. 58-1a-2-8-9-11 [12, Л. 233]. Дело было передано на рассмотрение в военную коллегию Верховного суда СССР по закону от 1 декабря 1934 г. Закрытое судебное заседание проходило на следующий день, 30 октября, с 9 до 9.20 часов. Несмотря на то, что на предварительном следствии Гольдберг признавал свою «вину», протокол судебного заседания свидетельствует о том, что «подсудимый виновным себя не признает. Свои показания на предварительном следствии отрицает, т.к. они даны неправильно, он дал их по уговору с сидящими в камере подсудимыми. Часть показаний он сам выдумал» [12, Л. 236-236об.]. С.В. Журавлев отмечал в своей работе, что подобная тактика была свойственна арестованным: они соглашались на все в ходе предварительного следствия, чтобы сохранить силы и здоровье, а на суде отказывались от показаний, но они не учитывали, что дела в основном рассматривались заочно, во внесудебном порядке [13, с. 176-177]. В данном случае отказ от показаний уже не мог спасти Гольдберга - его приговорили к высшей мере наказания, приговор был приведен в исполнение в этот же день. Отметим, что в приговоре значилась статья(и) 58-1a-89-11, то есть исчез заявленный в протоколе суда пункт 2 [12, Л. 237]. Мы предполагаем, что это произошло по невнимательности председателя суда. По информации базы данных «Мемориала», в этот день, 30 октября, Военная коллегия Верховного суда приговорила 12 человек - эта цифра не столь значительна, однако дает возможность предполагать, что не все выносимые на суд дела рассматривались внимательно. В отличие от «тройки», которая рассматривала дела конвейерным способом (в этот день «тройка» при УНКВД по Алтайскому краю вынесла 310 приговоров), суд должен был более тщательно относиться к следственным материалам.

Многие работники комбината, упомянутые Гольдбергом в его показаниях, впоследствии были арестованы. 29 марта 1937 г. был арестован заместитель начальника строительства БМК К. Буторов. Первые листы его следственного дела свидетельствуют о заведении данного дела, исходя не из реального обвинения, а из необходимости раскрытия уже «созданной» группы «правых». Справка на арест Буторова датирована 31 марта - на два дня позже, чем реально произошел арест. Суть обвинения против него состояла в том, что он был вовлечен Гольдбергом в активную контрреволюционную деятельность Сибирского центра правых и проводил контрреволюционную и подрывную работу на Меланжевом комбинате, в частности, срывал строительство жилых помещений для рабочих комбината и допустил перерасход по сметам. Внизу справки карандашом стоит отметка: «На 2.4.37 Гольдберг еще показаний на Буторова не давал» [14, Л. 2-3]. Вероятно, она могла появиться в процессе пересмотра дела в ходе реабилитации, но ее важность состоит в том, что она является свидетельством подготовки дела еще до того, как были получены «доказательства» вины. Если мы сделаем попытку реконструировать ход событий, он может выглядеть следующим образом: так как БМК постоянно обвиняли в притуплении классовой бдительности и засоренности «врагами», то невозможно было 


\section{Исторический журнал: научные исследования № 5 (35) • 2016}

DOI: 10.7256/2222-1972.2016.5.20378

бы предположить, что заместителя только что арестованного директора комбината оставят на свободе. Буторова арестовали 29 марта и, вероятно, до составления справки на арест ждали компрометирующих материалов - возможно также, пытались выбить показания из Гольдберга. В соответствии со ст. 106 Уголовно-процессуального кодекса РСФСР о задержании нужно было сообщить следователю или прокурору не позднее, чем через 48 часов, иначе арестованный может быть свободен. Вероятно, 31 марта следователи решили написать самое логичное обвинение о том, что заместитель вовлечен в контрреволюционную группу своим начальником, затем на допросе Гольдберга 4-5 апреля предъявили ему уже готовые показания. Также вероятно, что, если это действительно был подлог, он не отразился в тексте обвинительного заключения Гольдберга - среди людей, завербованных им, там не значится фамилия Буторова. При этом в деле Буторова присутствует справка о том, что срок следствия по его делу продлен от 17 марта 1937 г., когда он еще не был даже арестован [14, Л. 63].

Следующий момент, на который нужно обратить внимание - это статья в постановлении о предъявлении обвинения, датированном также 31 марта. Буторову инкриминировалось обвинение по статье 58-10-11. Если пункт 11 может быть обоснован его связью с Гольдбергом, то пункт 10 является явной припиской - ни в справке на арест, ни в данном постановлении нет свидетельств проведения антисоветской агитации. С.В. Журавлев отмечал, что для справок на арест характерна тенденциозность подбора фактов и обвинительный уклон: сотрудники НКВД стремились включить в нее максимум компрометирующей информации [13, с. 164]. Вероятно, что в таких искусственно созданных групповых делах в документах на арест статья обвинения могла содержать лишние пункты, которые отпадали в ходе выстраивания нужной линии следствия.

На допросе от 21 апреля 1937 г. Буторову напомнили о показаниях, данных им 13 апреля. Однако в деле нет такого протокола, о чем на листе есть карандашная пометка - «а где протокол 13 апреля» [14, Л. 13]. Тем не менее, обвиняемый показывал, что в 1931 г. он близко познакомился с секретарем обкома ВКП(б) Колотиловым. В процессе общения ему стало известно, что Колотилов и его товарищи являются сторонниками Бухарина. Колотилов охарактеризовал Гольдберга с положительной стороны и порекомендовал (по материалам дела - по прямому указанию Бухарина) ехать к нему для организации вредительства и срыва строительства комбината [14, Л. 14, 19, 24]. Достаточно сложно определить личность упоминаемого Колотилова: в обвинительном заключении Гольдберга он назван заведующим сельскохозяйственного отдела Крайкома ВКП(б), в базе данных «Мемориала» не содержится сведений о персоналиях с указанными должностями. Разговор Буторова и Колотилова происходил в Иваново-Вознесенске, следовательно, либо он также, как Буторов, переехал в Барнаул, либо в обвинительном заключении Гольдберга указан другой человек.

Следующий допрос Буторова проходил 8 сентября 1937 г. На нем он показал, что руководителем право-троцкистской организации был Гольдберг, а активными участниками группы К.Леонтьев, А. Наговицин, М.Резников, А. Торопцев (нет сведений об осуждении), Широков (нет сведений об осуждении), Б. Струков (начальник участка, арестован 28 июля 1937 г., приговорен и расстрелян 29 июня 1938 г.), В. Дородный (начальник сметного отдела, арестован 12 июня 1937, приговорен и расстрелян 29 июня 1938 г.). При этом Торопцева, Широкова и Струкова привлек в организацию лично Буторов [14, Л. 29]. Небольшой сбой «логики» следствия произошел по вопросу привлечения в организацию Дородного. Сам Буторов показал, что Дородный был вовлечен Леонтьевым, у которого он работал до 1936 г. [14, Л. 30], однако в деле Дородного сказано, что он был завербован Буторовым [15, Л. 24]. Он не отказывался от своих показаний, но в обвинительном заключении был зафиксирован именно второй вариант [14, Л. 70].

8 сентября Буторову было предъявлено новое обвинение по ст. 58-1а-2-8-9-11 [14, Л. 64], которое соответствовало обвинению Гольдберга согласно протоколу судебного заседания. Однако 26 октября следствие было завершено по ст. 58-8-11 [14, Л. 65]. Неизвестно, что происходило с обвиняемым в срок между предъявлением нового обвинения и окончанием следствия. В этот же день, 26 октября, было составлено обвинительное заключение. В нем в обвинении по статье от 8 сентября пункты 1а и 2 зачеркнуты, а 9 исправлена на 7 карандашом, следовательно, статья обвинительного заключения превратилась в 58-7-8-11. Можно предположить, что оно было составлено еще в сентябре до окончания следствия, в постановлении же от 26 октября об окончании следствия была до- 
пущена ошибка. В обвинительном заключении сообщалось, что политической целью правотроцкистского центра являлось провозглашение Сибирской республики в момент объявления войны при содействии Японии за счет территориальных компенсаций в Дальневосточной республике [14, Л. 67]. Указанное не согласовывалось с формулировками обвинительного заключения Гольдберга: там связи «устанавливались» с Германией, а также были предъявлены обвинения в шпионаже, в чем на предварительном следствии он признался. Буторову не задавали вопросов о шпионаже - вероятно, с этим связан отказ от инкриминирования пунктов 1а и 2 ст. 58. По указанной статье - 58-7-8-11 - Буторов был предан суду Военной коллегии и 27 октября 1937 г. приговорен к расстрелу, который был совершен в тот же день [14, Л. 67, 84].

По делу Гольдберга также был арестован М. Резников, инженер-технолог БМК. Его арест датирован 9 марта 1937 г. по ст. 58-10-11 [16, Л. 3, 5]. Более месяца после ареста допросы не проводились: в соответствии с материалами следственного дела 26 апреля 1937 г. он сам попросил вызвать его для дачи показаний. Прошение было удовлетворено только в июне [16, Л. 8-9] - вероятно, все это время следователи «сшивали» полученные от других обвиняемых показания в соответствии с определенной линией следствия. Любопытно, что фамилия Резникова прозвучала в показаниях Буторова накануне - 24 апреля.

Резников показал, что он был завербован в организацию Гольдбергом, а сам встал на путь контрреволюционной работы еще в 1927 г. благодаря знакомству с главарем троцкистской организации Токаревым, бывшим директором московского текстильного техникума (фамилию Токарева также упоминал в своих показаниях Буторов), студентом которого в то время являлся Резников. Гольдберг стал сближаться с ним в 1934 г., убеждая, что в партии отсутствует демократия, и, несмотря на возражения со стороны Резникова, продолжал его идеологическую обработку. «У меня возник известный рецидив, вызванный моим участием в троцкистской группе в техникуме. Я постепенно стал соглашаться и разделять контрреволюционные взгляды Гольдберга» - показывал Резнииков [16, Л. 16].

Следующий допрос проводился 8 сентября тогда же, когда допрашивали и Буторова. Резникову был задан вопрос о его шпионской работе, в проведении которой он не сознался [16, Л. 19]. Вероятно, именно в сентябре следствие решило провести еще одну «линию» данного дела: Гольдберг «сознался» в связях с Германией, Буторову не далось инкриминировать эти обвинения (ст. 58 п.1а и 2). Резникому, несмотря на отсутствие признания, 8 сентября было предъявлено обвинение по ст. 58-1a-2-8-9-11, однако, как и у Буторова, следствие было закончено 27 октября 1937 г. по ст. 58-8-11. 29 октября состоялся суд Военной коллегии Верховного Суда - на нем пункты статьи 58 обвинения снова поменялись: Резников был приговорен к расстрелу по ст. 58-1a-7-8-11 [16, Л. 72, 74-76]. Это обвинение практически идентично предъявленному Буторову, однако у последнего отсутствовал пункт $1 \mathrm{a}$ - измена Родине, в том числе шпионаж. Вероятно, что протоколы об окончании следствия по ст. 58-8-11 означали, что эти пункты обвинения полностью доказаны, остальное являлось «творчеством» следователей: Буторову не предъявляли обвинения в шпионаже, следовательно, не могли и судить по данным пунктам ст. 58. Резников не признался, однако сам факт вопросов о шпионаже подтверждает то, что это обвинение было «приписано» ему заранее. Также вероятно, что определенную роль в обвинениях о шпионаже сыграла национальность, которая даже сама по себе могла стать основанием для ареста в годы Большого террора: Гольдберг и Резников, в отличие от Буторова (русский), были евреями.

Обвиняемые по всем рассмотренным в данном исследовании делам были реабилитированы Советской властью во второй половине 1950-х - 1960 гг. за отсутствием состава преступления. На то, что эти дела были «придуманы» следователями в соответствии с определенными установками, указывают результаты нашего источниковедческого анализа. В деле Гольдберга и др. присутствует путаница с датами документов, статья обвинения меняется без сопутствующей этому процессу документации, показания обвиняемых разнятся между собой. Можно лишь предполагать, каким изощренным образом «добывались» необходимые следствию показания. Следствие велось с нарушением установленных правил и норм: согласно статье 116 уголовно-процессуального кодекса РСФСР, следствие не должно было продолжаться более двух месяцев с момента объявления постановления о привлечении лица в качестве обвиняемого. В следственных делах Гольдберга и др. не было указаний на сроки продления следствия в мае, когда заканчивался двухмесячный срок для арестованных в марте. В соответствии со ст. 245 УПК РСФСР, обвинитель- 


\section{Исторический журнал: научные исследования № 5 (35) • 2016}

DOI: $10.7256 / 2222-1972.2016 .5 .20378$

ное заключение должно было сообщаться под расписку каждому из подсудимых не позднее, как за трое суток до дня, назначенного для слушания дела. В делах Гольдберга и др. суд проходил на следующий день после составления обвинительного заключения. Такие грубые нарушения в ходе следствия, а также отсутствие разбирательств по ним еще раз свидетельствуют о том, что данное дело было от начала и до конца «придумано» работниками НКВД. Материалы рассмотренных нами дел показывают, как происходил процесс фабрикации дела, как формировались сети «пре- ступников». Также проясняется вопрос о том, как вдалеке от столицы местные органы НКВД изыскивали связи обвиняемых с известными антипартийными лидерами.

15 февраля 2016 г. благодаря фонду «Последний адрес» на доме, откуда 12 марта 1937 г. сотрудники НКВД забрали М.Е. Гольдберга и куда он больше никогда не вернулся (по адресу г. Барнаул, ул. Сизова, 26), была установлена мемориальная табличка, открытая в присутствии активистов движения, а также внучки Гольдберга М.Ю. Гольдберг [11].

\section{Библиография:}

1. Хаустов В., Самуэльсон Л. Сталин, НКВД и репрессии. М.: РОССПЭН, 2009. 432 с.

2. Западно-Сибирский край в цифрах, 1936 г.: Крат. стат. справ. / ЦУНХУ Госплана СССР. Зап.-Сиб. краев. упр. нар.-хоз. учета. Новосибирск : Зап.-Сиб. КУНХУ, 1936. 164 с.

3. Жертвы политических репрессий в Алтайском крае. 1931-1936. Т.2. Барнаул: Управление архивного дела администрации Алтайского края, 1999. 555 с.

4. Политические репрессии в Алтайском крае. 1919-1965. Барнаул: Администрация Алтайского края: Упр. арх. дела администрации Алтайского края, 2005. 428 с.

5. Гришаев В.Ф. Реабилитированы посмертно. Барнаул: Изд-во Алтайского государственного университета, 1995. 239 с.

6. ОСД УАДАК. Ф. Р-2. Оп. 7. Д. 833 по обвинению Пепеляевой, Бессонова, Гевлевой и др. по ст. 58-9.

7. Журавлев С.В. «НКВД напрасно не сажает»: особенности изучения следственного делопроизводства 1930-х гг. // Социальная история. Ежегодник. 2004. М.: Российская политическая энциклопедия (РОССПЭН), 2005. С. 371-400.

8. Государственный архив Алтайского края (ГА АК). Ф. П. 1. Оп. 1. Д. 22.

9. Данные по материалам базы данных «Мемориала» (Жертвы политического террора в СССР [Электронный ресурс]. 4-е изд. М., 2007).

10. ОСД УАДАК. Ф. Р. 618. Оп. 1. Д. 5. Запросы о соцпроисхождении и проверке автобиографических сведений сотрудников текстилькомбината.

11. За что судили директора меланжевого комбината и где в Барнауле установят особые таблички // Сайт фонда «Последний адрес». [Электронный ресурс]. - Режим обращения: http://www.poslednyadres.ru/articles/bmk.htm

12. ОСД УАДАК. Ф. Р. 2. Оп. 7. Д. 5138/4 по обвинению Гольдберга М.Е.

13. Источниковедение новейшей истории России: теория, методология и практика. М.: РОССПЭН, 2004. 744 с.

14. ОСД УАДАК. Ф. Р. 2. Оп. 7. Д. 5138/3 по обвинению Буторова К.Г.

15. ОСД УАДАК. Ф. Р. 2. Оп. 7. Д. 5138 по обвинению Дородного В.А.

16. ОСД УАДАК. Ф. Р 2. Оп. 7. Д. 5138/2 по обвинению Резникова М.Г.

\section{References (transliterated):}

1. Khaustov V., Samuel'son L. Stalin, NKVD i repressii. M.: ROSSPEN, 2009. 432 c.

2. Zapadno-Sibirskii krai v tsifrakh, 1936 g.: Krat. stat. sprav. / TsUNKhU Gosplana SSSR. Zap.-Sib. kraev. upr. nar.-khoz. ucheta. Novosibirsk : Zap.-Sib. KUNKhU, 1936. $164 \mathrm{~s}$.

3. Zhertvy politicheskikh repressii v Altaiskom krae. 1931-1936. T.2. Barnaul: Upravlenie arkhivnogo dela administratsii Altaiskogo kraya, $1999.555 \mathrm{~s}$.

4. Politicheskie repressii v Altaiskom krae. 1919-1965. Barnaul: Administratsiya Altaiskogo kraya: Upr. arkh. dela administratsii Altaiskogo kraya, 2005. $428 \mathrm{~s}$.

5. Grishaev V.F. Reabilitirovany posmertno. Barnaul: Izd-vo Altaiskogo gosudarstvennogo universiteta, 1995. $239 \mathrm{~s}$.

6. OSD UADAK. F. R-2. Op. 7. D. 833 po obvineniyu Pepelyaevoi, Bessonova, Gevlevoi i dr. po st. 58-9.

7. Zhuravlev S.V. «NKVD naprasno ne sazhaet»: osobennosti izucheniya sledstvennogo deloproizvodstva 1930-kh gg. // Sotsial'naya istoriya. Ezhegodnik. 2004. M.: Rossiiskaya politicheskaya entsiklopediya (ROSSPEN), 2005. S. 371-400.

8. Gosudarstvennyi arkhiv Altaiskogo kraya (GA AK). F. P. 1. Op. 1. D. 22.

9. Dannye po materialam bazy dannykh «Memoriala» (Zhertvy politicheskogo terrora v SSSR [Elektronnyi resurs]. 4-e izd. M., 2007).

10. OSD UADAK. F. R. 618. Op. 1. D. 5. Zaprosy o sotsproiskhozhdenii i proverke avtobiograficheskikh svedenii sotrudnikov tekstil'kombinata.

11. Za chto sudili direktora melanzhevogo kombinata i gde v Barnaule ustanovyat osobye tablichki // Sait fonda «Poslednii adres». [Elektronnyi resurs]. - Rezhim obrashcheniya: http://www.poslednyadres.ru/articles/bmk.htm

12. OSD UADAK. F. R. 2. Op. 7. D. 5138/4 po obvineniyu Gol'dberga M.E.

13. Istochnikovedenie noveishei istorii Rossii: teoriya, metodologiya i praktika. M.: ROSSPEN, 2004. $744 \mathrm{~s}$.

14. OSD UADAK. F. R. 2. Op. 7. D. 5138/3 po obvineniyu Butorova K.G.

15. OSD UADAK. F. R. 2. Op. 7. D. 5138 po obvineniyu Dorodnogo V.A.

16. OSD UADAK. F. R 2. Op. 7. D. 5138/2 po obvineniyu Reznikova M.G. 